Initial Approximation

$\begin{array}{lr}x & -2.3762 \\ y & 0.6367\end{array}$

\section{TABLE II \\ Newton-Raphson process}

$-2.4047$

0.5407

\author{
Richmond's \\ process
}

0.5398
Correct result

It will be noted that this root is not as accurately determined as were the real roots of $J_{0}(x)=0$. This is not essentially due to the fact that the computations take place in the complex plane, but due to a secondary consequence of this, namely that the initial approximation to the root is more inexact.

Scientific Computing Service Ltd.

\title{
P. WYNN
}

23, Bedford Square

London, W.C. 1, England

1. D. R. Hartree, "Notes on iterative processes," Cambridge Phil. Soc., Proc., v. 45, 1949, p. 230-236; see also E. SCHRöDER, "Über unendlich viele Algorithmen zür Auflösung der Gleichungen," Math. Ann., v. 2, 1870, p. 317-363. The possible ambiguity in our definition of convergence of order $k$ is not significant in the present context.

2. H. W. RICHMOND, "On certain formulae for numerical approximation," London Math. Soc., Jn., v. 19, 1944, p. 31-38.

3. HaRVARD UnIVERsity, Tables of the Bessel Functions of the First Kind of Orders Zero and One, v. 3, Harvard Univ. Press, Cambridge, 1947.

4. Columbia University, Table of the Bessel Functions $Y_{0}(z)$ and $Y_{1}(z)$ for Complex Arguments, Columbia Univ. Press, New York, 1950.

5. Columbia University, Table of the Bessel Functions $J_{0}(z)$ and $J_{1}(z)$ for Complex Arguments, Columbia Univ. Press, New York, 1943.

\section{REVIEWS AND DESCRIPTIONS OF TABLES AND BOOKS}

33[A].-EDGAR KARST, $A$ simple octal (binary) multiplication method for checking computer results. 4 leaves, handwritten, deposited in the UMT FILE.

In this octal multiplication method, sums of one-digit products are accumulated mentally, with two intermediate lines being written.

\section{J. L. Selfridge}

University of California

Los Angeles, California

34[A-F, HI, K-N, P-V, Z].-KARL SchüTTE, Index Mathematischer Tafelwerke und Tabellen (Index of Mathematical Tables), R. Oldenbourg, München, 1955, 143, p., $21 \mathrm{~cm}$. Canvas cover. Price, DM 14.50.

This is a booklet of 143 pages which consists of the following parts : A list of approximately 1,200 tables and other useful books classified under 16 general headings, an index of authors of these books and tables, and an index of institutes referred to in the first part.

The headings of the 16 classes are as follows: I. Numerical and practical calculating, II. Logarithms of natural numbers, III. Logarithms of circular functions, IV. Natural values of circular functions, V. Simple functions derived from elementary functions, VI. Primes, prime factors, factors, compound interest and rent; continued fractions, theory of numbers, VII. Factorials, gamma functions, exponential and hyperbolic functions; elementary transcendental functions, VIII. 
Elliptic functions and integrals, spherical, Bessel and other higher functions, IX. Integral tables and other higher functions; numerical solution of equations and differential equations, $\mathrm{X}$. Tables applicable to physics, chemistry, and other sciences, XI. Astronomy and astrophysics, XII. Geodesy and geophysics, XIII. Nautical and aeronautical determination of position, XIV. Meteorology, XV. Astronautics, XVI. Miscellaneous, formulas and tables of measures, weights, monetary units.

There is a preface in both English and German and the Table of Contents is also bilingual, as are the headings and subheadings of the first part. In addition, there is a list of the abbreviations used in the book.

The avowed purpose of this volume is essentially the same as that of the earlier Index of Mathematical Tables, written by Fletcher, Miller, and Rosenhead, (MTAC, 1946-47, v. 2, p. 13-18, 136, 178-181, 219-220, and 277-8). The book contains material dated as late as 1955 . However, the author states that the work was started before World War II and subsequently extended to 1955 . Thus, it presumably covers 11 years (or almost 11 years) of publication time since the publication of Fletcher, Miller, and Rosenhead.

The 16 large headings are broken down into a total of 130 subdivisions. For example, category III. Logarithms of circular functions, has 2 major headings, namely, A. Sexagesimal arguments, and B. Centesimals (grades), Sexagesimal and centesimal arguments. Under A, the subheadings are degrees, time, degree and time, decimals of degree, and decimals of degree and time. Under heading B, the subheadings are Centesimal arguments (grades), and Sexagesimal and centesimal arguments (grades).

Within each of the 130 subdivisions (as appropriate), the titles are arranged in increasing order of the number of decimal places contained therein and within each group where the number of decimal places remains fixed the titles are arranged in chronological order.

Of the approximately 112 pages of indexed tables and books, 42 of them represent tables and books in categories 10 through 15, i.e., tables applicable to physics, chemistry, biochemistry, biology, paleozoology, technics and engineering, astronomy and astrophysics, geodesy and geophysics, nautical and aeronautical determination of position, meteorology and astronautics. Examination of these 7 categories leaves the impression that most of the tables indexed hereunder are "nonmathematical" in character, i.e., handbooks and special technical tables and the like. If the number of titles is approximately proportional to the number of pages, this means that only about 750 of the approximately 1200 indexed titles are "mathematical" in nature.

The approximately 450 titles in categories $10-15$ are obviously useful information and probably such an index has not heretofore appeared in print. Certainly these categories are largely noncompetitive with the earlier index of Fletcher, Miller, and Rosenhead.

With respect to the approximately 750 titles of a "mathematical" nature, a sampling shows that probably between 50 and 60 per cent of them are dated 1944 and earlier and hence are within the purview of the Fletcher, Miller, and Rosenhead index. A finer examination of a few categories which can be compared with the Fletcher, Miller, Rosenhead index (namely, natural logarithms, natural 
circular functions (degrees and decimals), hyperbolic functions of real arguments and their logarithms, elliptic functions and integrals, Bessel functions of real arguments) shows that in the 1944 and earlier category, Schütte has 42 titles as opposed to at least 140 titles in Fletcher, Miller, and Rosenhead. Furthermore, of the 42 titles appearing in Schütte in these categories, 31 also appear in Fletcher, Miller, and Rosenhead. If the percentages showing up in this sample persist, this would indicate that in the mathematical categories approximately three-fourths of the titles which are dated 1944 and earlier are duplicates of those appearing in Fletcher, Miller, and Rosenhead. The reviewer had no time to make a complete item count and does not know whether the particular categories picked for sampling are typical or not.

The reviewer is somewhat disappointed that many of the desirable features of Fletcher, Miller, and Rosenhead index are not included in this book. For example, there is no indication whether an item has actually been seen by the author. There is no indication of the interval or range of the arguments. There is also no indication of the facilities provided for interpolation in tables, or any explanation of the varying notation, etc. The "standard" or "classical" tables in a given category are not set forth in boldface type as they are in the F.M.R. index. It would seem also that some kind of decimal classification system would be desirable.

There are some relatively minor things which undoubtedly will be corrected in subsequent editions of the book. Some misspellings occur (p. 55, change DeLalla to DeLella; p. 83, change Salva to Salvo; p. 138 , change J. M. Hammerley to J. M. Hammersley). In addition, there are probably a few incorrect titles (for example, on p. 55, the book listed as "8-figure values of the trigonometrical functions at interval $0^{\circ} .01$," by E. Buckingham probably is section 1 of the Manual of Gear Design written by Mr. Buckingham). A finer breakdown of categories would certainly be useful in many instances (for example, in the case of hyperbolic functions one might want to know which hyperbolic functions are tabulated in a particular place).

The book will undoubtedly serve a useful purpose since it does have material not available elsewhere. However, it is a little disappointing that the same care and precision did not go into its preparation as went into the F.M.R. Index, in favor of which the reviewer may very well be prejudiced.

University of California

Thomas H. Southard

Los Angeles, California

35[E].- NBS Applied Mathematics Series No. 45, Table of Hyperbolic Sines and Cosines, $x=2$ to $x=10$, U. S. Gov. Printing Office, Washington, D. C., 1955, $\mathrm{v}+81 \mathrm{p} ., 25.7 \mathrm{~cm}$. Price, 55 cents.

This table lists $\sinh x$ and $\cosh x$ for $x=2(.001) 10,9 \mathrm{~S}$.

It is an extension to AMS 36, Tables of Circular Hyperbolic Sines and Cosines for Radian Arguments, and its predecessor volume, Mathematical Tables 3, see Reviews $89, M T A C$, v. 1,1943 , p. $45-7$, and 33, $M T A C$, v. 9, 1955, p. 71-2, and note 114, $M T A C$, v. 4, 1950, p. 123-4. AMS 36 and its predecessors list, among other things, $\sinh x$ and $\cosh x$ for $x=0(.0001) 1.9999,9 \mathrm{D}$. 
There is adequate introduction. Here the addition formulas used in the computation of the table are stated, it is remarked that linear interpolation will yield at least six significant digits throughout, and quadratic interpolation formulas accurate to the full nine significant digits are stated.

In addition, it is remarked in the introduction that $\frac{1}{2} e^{x}$ is a $9 \mathrm{~S}$ approximation for both $\sinh x$ and $\cosh x$ for $x>10$.

In the introduction it is claimed that the error in tabulated values should be no more than a unit in the last place given. As a matter of routine, Mrs. R. B. Horgan and Mr. Edward Sallin recomputed the values for 200 randomly chosen arguments taken from [1]; they discovered 12 cases in which sinh $x$ disagreed with the values in AMS 45 and 6 cases in which $\cosh x$ disagreed with the values computed in AMS 45. Their calculation was based on the values listed in the basic table by C. E. Van Orstrand [2]. The discrepancies are all 1 unit in the last place, which is within the accuracy claimed in AMS 45.

The table was computed on the National Bureau of Standards Eastern Automatic Computer (SEAC) by William F. Cahill. The results are transcribed onto punched cards, the values in these cards were then differenced, and the manuscript was prepared on the card-controlled typewriter at the National Bureau of Standards. The photographic reproduction is excellent, both in format and legibility. below.

The slight discrepancies noted by Mrs. Horgan and Mr. Sallin are tabulated

C. B. T.

\begin{tabular}{|c|c|c|}
\hline \multicolumn{3}{|c|}{ TABLE 1} \\
\hline & $\begin{array}{c}\text { TABLE } 1 \\
\sinh x\end{array}$ & \\
\hline$x$ & $\sinh x$ from AMS 45 & $\sinh x$ from SWAC \\
\hline $\begin{array}{l}2.914 \\
3.388 \\
4.162 \\
4.843 \\
5.404 \\
6.046 \\
6.641 \\
6.882 \\
7.060 \\
8.190 \\
8.556 \\
8.572\end{array}$ & $\begin{array}{rl}9.18805 & 728 \\
14.78645 & 18 \\
32.09210 & 88 \\
63.42072 & 31 \\
111.14465 & 9 \\
211.20880 & 0 \\
382.92958 & 3 \\
487.28626 & 7 \\
582.22215 & 4 \\
1802.36099 & \\
2598.92398 & \\
2640.84121 & \end{array}$ & $\begin{array}{rl}9.18805 & 727 \\
14.78645 & 17 \\
32.09210 & 87 \\
63.42072 & 30 \\
111.14465 & 8 \\
211.20879 & 9 \\
382.92958 & 2 \\
487.28626 & 6 \\
582.22215 & 3 \\
1802.36098 & \\
2598.92397 & \\
2640.84120 & \end{array}$ \\
\hline & $\begin{array}{c}\text { TABLE } 2 \\
\cosh x\end{array}$ & \\
\hline$x$ & $\cosh x$ from AMS 45 & $\cosh x$ from SWAC \\
\hline $\begin{array}{l}4.617 \\
5.101 \\
5.914 \\
8.510 \\
8.824 \\
9.247\end{array}$ & $\begin{array}{rl}50.59994 & 44 \\
82.09605 & 10 \\
185.09331 & 8 \\
2482.08165 & \\
3397.69603 & \\
5186.69945 & \end{array}$ & $\begin{array}{rl}50.59994 & 43 \\
82.09605 & 09 \\
185.09331 & 7 \\
2482.08164 & \\
3397.69602 & \\
5186.69944 & \end{array}$ \\
\hline
\end{tabular}


1. The RAND Corporation, A Million Random Digits with 100,000 Normal Deviates, The Free Press, 1955, Review 11, $M T A C$, v. 10, 1956, p. 39-43.

2. C. E. VAN ORSTRAND, "Tables of the exponential function and of the circular sine and cosine to radian argument," Nat. Acad. Sci. Memoirs, v. 14, 1921, Fif th memoir.

36[E].-NBS Applied Mathematics Series No. 46, Table of the Descending Exponential, $x=2.5$ to $x=10$. U. S. Gov. Printing Office, Washington, D. C., 1955, v +76 p., $25.7 \mathrm{~cm}$. Price, 50 cents.

This table lists $e^{-x}, x=2.5(.001) 10,20 \mathrm{D}$. There is a short introduction, which describes the computation and printing of the table but otherwise refers the reader to an earlier volume [1].

Calculations were performed on the SEAC computer to $25 \mathrm{D}$, rounded to $20 \mathrm{D}$, differenced for checking (no differences are published), and typed by a card-controlled typewriter (presumably the IBM model 058 at the National Bureau of Standards) for photographic reproduction.

This publication is considered to be auxiliary to [1], which lists (among other things) $e^{-x}, x=0(.0001) 2.4999,18 \mathrm{D}$. In the brief introduction the reader is referred to this earlier volume for bibliographic notes and other information.

As a matter of routine, Mrs. R. B. Horgan and Mr. Edward Sallin used the SWAC computer to check the values at 200 randomly chosen arguments (taken from [2]) against products of the values listed by Van Orstrand [3]; there were no discrepancies between the listed values and the values computed on SWAC.

The printing is easily legible and entirely satisfactory.

$$
\text { C. B. T. }
$$

1. National Bureau of Standards Applied Mathematics Series 14, Tables of the Exponential Function $e^{x}$, U. S. Government Printing Office, 1951, reviewed in an earlier edition, RMT 524, $M T A C$, v. 3, 1948-9, p. 173.

2. The RAND Corporation, A Million Random Digits with 100,000 Normal Deviates, The Free Press, 1955, Review 11, $M T A C$, v. 10, 1956, p. 39-43.

3. C. E. VAN ORSTRAND, "Tables of the exponential function and of the circular sine and cosine to radian argument," Nat. Acad. Sci. Memoirs, v. 14, 1921, Fif th memoir.

37[G].-J. D. Swift, Tables of Steiner Triple Systems, 4 p., 28 cm., +7 p., 56 cm., manuscript. Deposited in UMT FILE.

These tables list one sytem of each class of isomorphic Steiner triple systems of orders $3,7,9,13$, and 15 . Some algebraic and classification data are included in the listings.

There is only one class for each of the orders 3,7 , and 9 ; there are two classes of order 13 ; there are 80 classes of order 15.

The 4 small pages contain introductory and description material and the tables through those of order 13. The 7 large pages contain the table of the 80 classes of order 15 .

Part of the material was computed by the author and a colleague in connection with their paper on Steiner triple systems of order 15 [1]. Material was also taken from a listing of systems order 13 by F. N. Cole [2]. Cross references are made to papers by A. S. White, F. N. Cole, and Louise B. Cummings [3], and R. A. Fisher [4].

$$
\text { C. B. T. }
$$

1. Marshall Hall, JR., \& J. D. Swift, “Determination of Steiner triple systems of order 15," $M T A C$, v. 9,1955, p. $146-152$. 
2. F. N. Cole, "The triad systems of 13 letters," Am. Math. Soc., Trans., 1913, v. 14, p. 1-5.

3. A. S. White, F. N. Cole, \& Lourse D. Cummings, "Complete classification of triad systems on 15 elements," Nat. Acad. Sci., Memoirs, v. 14, 1925, 2nd Memoir, 89 p.

4. R. A. FISHER, "An examination of the different possible solutions of a problem in incomplete blocks," Ann. of Eugenics, v. 10, 1940, p. 52-75.

38[G, H, I, J, L, M].-Andrew D. Booth, Numerical Methods, Academic Press, New York, Butterworth, London, 1955, viii +195 p., $8 \frac{1}{2}^{\prime \prime} \times 5 \frac{1}{2}^{\prime \prime}$. Price, $\$ 6.00$.

Dr. Bootii has a reputation [1] in X-ray crystallography, in the design and construction of what his publisher [2] calls "authentic" calculating machines, and in their use, e.g., in language translation. Unfortunately this book is not up to his usual standards. There are many signs of hasty writing and referencing, careless proofreading, and unfamiliarity with current typographical conventions [3]; indeed Dr. Booth appears to be unsure of the initials of his wife and collaborator (p. 190,191). In addition there are substantial inaccuracies at various levels.

Among the errors which have caught our eye we mention the following:

On p. 38, there is the standard classroom mistake of assuming that the mean value $\xi$, in the error term of a Maclaurin series for $f(x)$, is independent of $x$, and taking it outside the sign of integration.

On p. 59 and elsewhere we find error terms in approximate quadratures given as $A h^{n} f_{\max }^{n}$ instead of $\theta A h^{n}\left|f^{n}\right|_{\max }$ with $0 \leqslant|\theta| \leqslant 1$.

On p. 92 there is the suggestion that every orthogonal matrix is symmetric.

We quote, without comment and with the author's spelling, the first sentence of section 7.12 entitled Monte Carlo Methods, and the footnote to which reference is made: "The somewhat intriguing title of this section is now applied to methods of numerical analysis which make use of the theory of Games [12]. ((12) von Neumann, J., and Morganstern, O., The Theory of Games, Princeton (1947))."

It is dangerous to recommend methods for the solution of particular problems in numerical analysis, such as the inversion of matrices and the determination of their eigenvalues, without a knowledge of personnel, equipment available, and of the details of the problem. Our experience does not always coincide with that of Dr. Booth.

Nothing less than a complete revision of the book can make it acceptable in its purpose to reveal to final honors B.Sc. students at the University of London the basic mathematical principles of modern computation.

The chapter headings are: The Nature and Purpose of Numerical Analysis; Tabulation and Differences; Interpolation; Numerical Differentiation and Integration; The Summation of Series; The Solution of Ordinary Differential Equations; Simultaneous Linear Equations; Partial Differential Equations; Nonlinear Algebraic Equations; Approximating Functions; Fourier Synthesis and Analysis; Integral Equations.

J. T.

1. A. D. Bоотн, Fourier Technigue in X-ray Organic Structure Analysis, Cambridge, 1948. 1953

A. D. Воотн \& K. H. V. Booth, A utomatic Digital Calculators, Butterworths Sci. Pub., London,

W. N. Locke \& A. D. Booth, editors, Machine Translation of Language, John Wiley and Sons, New York, 1955.

2. Nature, Butterworths Scientific Publications Advertisement, v. 175, 1955, p. ccccxli. 
3. For instance, on one opening, p. 62-63, we find three ways of indicating the tail of an infinite series: $+\cdots,+$ etc., $\cdots$; on p. 53 we find + etc., $\cdots, \cdots$ etc.

Again we find $O\left(x^{r}\right)$ signifying a polynomial of degree $r$; elsewhere we find $O(10)$.

The reviewer would like to include a disclaimer on the part of SEAC to the discovery of the fifteenth Mersenne prime. That $2^{1279}-1$ is prime was established by SWAC (see $M T A C, 6,1952$, p. 205), not by SEAC, as stated on p. 2 .

39[G, H].-Proceedings of the Conference on Linear Programming, May, 1954, FErranti Ltd., London, England, 1955, 92 mimeographed p., $32.3 \mathrm{~cm}$. A limited number of copies are available free from Ferranti Ltd., 21 Portland Place, London W. 1, England.

Ferranti Ltd., which has been constructing high-speed automatic computers, issued this report of a conference on linear programming which it sponsored on May 4, 1954. Of the eight papers presented, two deal with computation, the remainder with applications. E. M. L. Beale outlines his "method of leading variables," previously reported in more detail in [1], and presents worksheets of a numerical example. D. G. Prinz describes experiences on the Manchester Computer with the Simplex Method, using the version of the method in which the entire tableau is transformed. He remarks that some difficulties due to round off occurred when numbers conceptually zero were not actually zero in the machine. These were eliminated by modifying the code so that the conceptual zeros were never entered. The paper also offers a brief heuristic justification for the fact that, characteristically, the simplex method takes fewer iterations than the conceivable upper bound (unknown, by the way), but the argument is not very convincing.

National Bureau of Standards

A. J. Hoffman

Washington, D. C.

1. E. M. L. BEALE, "An alternative method for linear programming," Camb. Phil. Soc., Proc., v. 50,1954, p. $513-523$.

40[H].-MARK Lotkin, "A set of test matrices," 10 p., $27 \mathrm{~cm}$. Typescript deposited in the UMT FILE.

Table 1 contains inverses of $A_{n}, N=1(1) 10$. This requires 4 pages. Table 2 lists the matrices $H_{n}, N=1(1) 10$. This requires 5 pages. Table 3 lists characteristic polynomials $F_{n}(\lambda), N=1(1) 6$. This requires about a third of a page.

The matrix $A_{n}$ is defined in the author's paper [1], p. 153; $H_{n}$ is defined in [1], p. 158; the characteristic polynomials are for the matrices $A_{n}$.

1. MARk Lotkin, "A set of test matrices," $M T A C$, v. 9, 1955, p. 153-161.

C. B. T.

41[L].-HARold D. LARSEN, Rinehart Mathematical Tables, Formulas and Curves, Enlarged Edition, 1953, reprinted 1956. Rinehart \& Co., Inc., New York, viii $+280+2$ p., $21 \mathrm{~cm}$. Price $\$ 2.50$.

Seven tables, 28-34, have been added to the earlier edition $(M T A C$, v. 3 , 1949, p. 466) as follows:

T. 28: Values and Common Logarithms of the Gamma Function, $\Gamma(n), 5 \mathrm{D}, n=1.01(.01) 2.50$.

T. 29: The Probability Integral, $\frac{2}{\sqrt{\pi}} \int_{0}^{t} e^{-t^{2}} d t, 5 \mathrm{D}, t=0(.001) 2(.01) 3.09$. 
T. 30: Values of Bessel Functions $J_{0}(x)$ and $J_{1}(x), 4 \mathrm{D}, x=0(.1) 14.9$; also smallest six positive zeros of $J_{0}(x)$ and $J_{1}(x)$.

T. 31: Values of the Complete Elliptic Integrals,

$$
\begin{aligned}
& K=\int_{0}^{\pi / 2}\left(1-\sin ^{2} \theta \sin ^{2} \phi\right)^{-\frac{1}{2}} d \phi, \\
& E=\int_{0}^{\pi / 2}\left(1-\sin ^{2} \theta \sin ^{2} \phi\right) d \phi, 4 \mathrm{D}, \\
& \theta=0^{\circ}\left(1^{\circ}\right) 70^{\circ}\left(0.5^{\circ}\right) 80^{\circ}\left(0.2^{\circ}\right) 89^{\circ}\left(0.1^{\circ}\right) 90^{\circ} .
\end{aligned}
$$

T. 32: Values of the Elliptic Integral of the First Kind,

$$
\begin{aligned}
F(k, \phi) & =\int_{0}^{\phi}\left(1-\sin ^{2} \theta \sin ^{2} \phi\right)^{-\frac{1}{2}} d \phi, 4 \mathrm{D}, \\
\theta & =5^{\circ}\left(5^{\circ}\right) 90^{\circ}, \quad \phi=1^{\circ}\left(1^{\circ}\right) 90^{\circ} .
\end{aligned}
$$

T. 33: Values of the Elliptic Integral of the Second Kind,

$$
\begin{aligned}
& E=(k, \phi)=\int_{0}^{\phi}\left(1-\sin ^{2} \theta \sin ^{2} \phi\right)^{\frac{1}{3}} d \phi, 4 \mathrm{D}, \\
& \theta=5^{\circ}\left(5^{\circ}\right) 90^{\circ}, \quad \phi=1^{\circ}\left(1^{\circ}\right) 90^{\circ} .
\end{aligned}
$$

T. 34: Square Root Divisors (for Calculating Square Roots to 5 Significant Figures).

The typography and composition of the tables are good and pleasing to the eye of the user. It is certainly appropriate to have tables of such things as the Incomplete Elliptic Integrals of the First and Second Kinds available among a collection of elementary tables.

Several relatively minor things may be worthy of correction in the next edition. In T. 29 and T. 32-3, it is not necessary to use the same letter for the upper limit and the variable of integration. In T. 32-3, the functions actually tabulated are $F(\theta, \phi)$ and $E(\theta, \phi)$ respectively instead of those advertised, viz., $F(k, \phi)$ and $E(k, \phi)$. For completeness and use in interpolation, it would be nice to have included $\theta=0^{\circ}$ and $\phi=0^{\circ}$ among the arguments; however, these entries are easily computed and further, their inclusion would have used more space and, in the case of $\theta=0^{\circ}$, would probably have necessitated an additional page in each table.

T. 34 appears to be of doubtful utility. With the use of Table 4 and "visual interpolation," one can usually obtain $\sqrt{N}$ to $4 \mathrm{~S}$. Following this with one division, Newton's method $\left[x_{K+1}=\frac{1}{2}\left(x_{K}+\frac{N}{x_{K}}\right)\right]$ gives 7S or 8S. However, the reviewer is willing to be convinced by the results of a "challenge match." 
42[L].-Gertrude Blanch \& IdA Rhodes, "Table of characteristic values of Mathieu's equation for large values of the parameter," Washington Academy of Sciences, Jn., v. 45, 1955, p. 166-196.

The tabulation presented in this paper complements the NBS tables ( $M T A C$, v. 6, 1952, p. 29-30), and completes the tabulation of characteristic values of Mathieu's equation for all orders $r \leq 15$. The notations are the same as in the NBS tables, except that the auxiliary parameter $t$ has been used in place of $s=1 / t^{2}$, and the quantities

$$
\mathrm{Be}_{r}(t)=\mathrm{be}_{r}(s)-(2 r+1) / t, \quad \mathrm{Bo}_{r}(t)=\mathrm{bo}_{r}(s)-(2 r-1) / t
$$

have been tabulated in place of the characteristic values.

The chief aim was a numerical description of the characteristic values for $r=0(1) 15$ and $s \geq 100$, or $t \leq .1$. The intervals have been so chosen that interpolation by Everett's formula with second and fourth modified central differences will give full accuracy; and the requisite differences are given in the tables. All entries are given to $8 \mathrm{D}$, and for $t \geq .01$ all entries should be correct, but the authors are careful in pointing out that their method of checking made it impossible to detect a random error of two units of the last decimal place. For $t<.01\left(s>10^{4}\right)$, the accuracy is considerably less, and even the seventh decimal place cannot be guaranteed. However, in this range, $6 \mathrm{D}$ in $\mathrm{B}_{r}(t)$ mean at least $9 \mathrm{~S}$ in $b_{r}(t)$.

The authors have produced a very useful set of tables. It is to be hoped that numerical work on Mathieu functions will continue with emphasis, in the future, on functions of higher orders.

California Institute of Technology

A. ERnÉLYI

Pasadena, California

43[Q].-Admiralty Hydrographic Supplies Establishment, Tables of Computed Altitude and Azimuth, v. I : Latitudes $0^{\circ}-14^{\circ}$ North and South. Hydrographic Publication H.D. 486/1, Hydrographic Dept., Admiralty, London. England, 1952, xvi +351 p., $29.5 \mathrm{~cm}$. Each volume is priced at $30 \mathrm{~s}$. 0d. an copies may be obtained from Admiralty Chart Agents, the Admiralty Hydr graphic Supplies Establishment, Creechbarrow House, Taunton, and from any Admiralty Chart and Chronometer depot.

The U. S. Hydrographic Office Publication No. 214 has been reproduced in Tables of Computed Altitude and Azimuth by the British Hydrographic Department. The original H.O. 214 is in nine volumes, each covering $10^{\circ}$ of latitude. The regrouping of the new edition results in six volumes, each covering $15^{\circ}$. The tabular matter is identical in both, except that certain errors have been corrected in the British publication. (These are listed, for Vol. 1, on page xvi of the Introduction.)

The tables are designed to solve directly the spherical triangle of astronomy. Latitude, declination, and hour angle are the arguments, yielding altitude and azimuth of the object under observation. Computed altitudes less than $5^{\circ}$ are 
omitted, and no refraction is included in the tabulated values. Altitudes are printed to the nearest tenth of a minute of arc, azimuths to the nearest tenth of a degree.

Latitudes and hour angles are given at intervals of $1^{\circ}$; declinations at various intervals, but not less than $30^{\prime}$. The choice of declination values was made appropriate to the positions of the Sun, Moon, planets, and the principal navigation stars. Thus, the interval is uniformly $30^{\prime}$ up to $30^{\circ}$ declination. Above this value there are places where very large intervals occur, e.g., between $63^{\circ}$ and $69^{\circ}$ declination. This might cause inconvenience in other applications of the tables than that for which they were designed.

As an aid to interpolation for the actual declination and local hour angle two auxiliary quantities $\Delta d$ and $\Delta t$ are given. These represent, respectively, the change of altitude in minutes of arc for one minute change in declination, and the change in altitude for a one minute change in hour angle. A multiplication table is printed on the end papers to facilitate interpolation.

A complete description is given of the use of the tables, consistent with navigation practice in the British Navy.

University of California

F. H. Hollander

Los Angeles, California

44[Q].-Admiralty Hydrographic Supplies Establishment, Sight Reduction Tables for Air Navigation, v. 1 : Selected Stars for Epoch 1955.0, 1952, xi + 324 p., $29.5 \mathrm{~cm}$.; v. 2 : Latitudes $0^{\circ}-39^{\circ}$, Declinations $0^{\circ}-29^{\circ}$; v. $3:$ Latitudes $40^{\circ}-89^{\circ}$, Declinations $0^{\circ}-29^{\circ}, 1953, \mathrm{x}+338$ p., $29.5 \mathrm{~cm}$. A.P. 3270 . H.M. Nautical Almanac Office, Herstmonceux Castle, Sussex, England. Each volume is priced at 30s. Od. and copies may be obtained from Admiralty Chart Agents, the Admiralty Hydrographic Supplies Establishment, Creechbarrow House, Taunton, and from any Admiralty Chart and Chronometer depot.

These three volumes represent a joint effort of the U. S. Nautical Almanac Office, and H. M. Nautical Almanac Office. They are issued in the United States as Hydrographic Office Publication No. 249.

Volume 1. Values of altitude, to the nearest minute of arc, and true azimuth, to the nearest degree are given for six selected stars for every degree of latitude and local hour angle of the first point of Aries. (Above latitude $70^{\circ}$ the local hour angle is given at intervals of $2^{\circ}$.) The stars were chosen to be those best placed for observation at any given time and place. The tables are arranged so as to provide for a change in the choice of stars every hour, if necessary (every two hours, above $70^{\circ}$ latitude). As the star positions are affected by proper motion of the stars themselves it is planned to issue a new edition of this volume every five years. No refraction has been applied to the tabulated altitudes.

These tables are of limited value outside their intended area of operation which is the planning of observations for aircraft flights, and their subsequent reduction. (Various auxiliary tables are given on the end papers. These include a table to aid interpolation, one for conversion of angles of arc to time, a refraction table, and a table of Coriolis corrections.) 
The British edition is reproduced from the plates of H.O. 249. The tables were originally prepared at the U. S. Nautical Almanac Office of the U. S. Naval Observatory. The computations were performed on punched cards, and the printers' copy was prepared on a card-operated typewriter at the Naval Observatory. Photographic offset reproduction was used.

Volumes 2 and 3. These are permanent tables for the reduction of aeronautical observations of the Sun, Moon, and planets. The arguments are declination: $0^{\circ}\left(1^{\circ}\right) 29^{\circ}$, and latitude : $0^{\circ}\left(1^{\circ}\right) 89^{\circ}$. The third argument is local hour angle, at intervals of $1^{\circ}\left(2^{\circ}\right.$ above latitude $\left.70^{\circ}\right)$. Volume 2 covers latitudes from $0^{\circ}$ to $39^{\circ}$, volume 3 from $40^{\circ}$ to $89^{\circ}$. Altitude and azimuth are given to the nearest minute of arc, and nearest degree, respectively. A column of differences of altitude is given for horizontal interpolation from one declination to the next higher one.

An interesting feature is the extension of the tabulated altitudes to negative values for the reduction of solar and lunar observations made at the high levels of flight of modern aircraft. A table of the Greenwich Hour Angle and Declination of the Sun for the years 1953-2000 is given at the back of each volume. Other tables, on the end papers, are similar to those of volume 1.

The method of preparation, using punched cards, was the same as for the first volume. Proofreading on all three volumes was facilitated by the comparison of cards punched from proof with those used in the preparation of printers' copy.

This helps to explain why the only errata listed are for figures not clearly printed, and which may be misread.

University of California

F. H. Hollander

Los Angeles, California

45[Q].-SAmUel Herrick, "Tables for rocket and comet orbits," National Bureau of Standards AMS No. 20, U. S. Gov. Printing Office, Washington, 1953, xxiv + 100 p., $26.7 \mathrm{~cm}$. Price $\$ 1.75$.

In Dynamical Astronomy, and more recently in rocketry, the solution is frequently required of the equation, $E-e \sin E=M$ (or the corresponding equations for parabolic or hyperbolic motion). This is known as Kepler's Equation, and reputedly more than 300 papers have been written on this subject. Now comes another.

The justification of this one lies in the following considerations. When " $e$ " is small, one encounters no difficulty in solving by successive approximations, using an ordinary table of sines. As " $e$ " approaches unity, the number of decimals required near the front of the table becomes inordinately large in order to reach a comparable accuracy, since one essentially uses $(E-\sin E)$. The author has therefore chosen $(E-\sin E)$ as the argument of his tables, and the respondents are $(1-\cos E), \sin E$, and $E$ (with corresponding functions for the other two types of motion). The difficulty with the decimal point cannot be overcome, but it is rendered less obtrusive by assigning "ranges" to the argument.

The Introduction is exceedingly lucid and detailed. The author emphasizes the relation of his concept to rectilinear motion, in contrast to the usual approach, 
which is related to parabolic motion. Illustrations are given to match those of Bauschinger's classical astronomical treatise.

The tables are clearly printed by photo-offset from copy prepared on a punched-card controlled typewriter. Presumably there are no typographical errors, if this process is properly prosecuted. The actual calculations were carried out under the supervision of Dr. Gertrude Blanch, for the most part on an IBM 602 Multiplier. The interval of the argument varies throughout the table in such a fashion that interpolation is rendered uniform with first and modified second differences. Unfortunately, it was not considered feasible to print the one hundred entries of the Everett second difference coefficients on one page, or even on one opening.

The application to rockets, as the title imples, is not immediately apparent. The only times during which rockets are in rectilinear motion they are subjected to such strong forces of thrust or drag that the ordinary equations of two-body motion do not apply. The recently proposed artificial satellite will most certainly have an " $e$ " less than 0.1 , and even an intercontinental ballistic missile on any kind of a reasonable trajectory has a moderate eccentricity. If some future space cadet sets his rocket ship into rectilinear motion with respect to the Sun, he is surely doomed to perdition in a very real sense.

Cincinnati Observatory

Paul Herget

Cincinnati, Ohio

46[S, T].-Beatrice H. Worsley, "Solutions of a nonlinear differential equation arising in the theory of diffusion flames," $M T A C$, v. 9, 1955, p. 112-116.

The paper describes a numerical method of solving the equation

$$
v^{\prime \prime}=\frac{k}{x+x_{1}} v\left(v+x+x_{1}-1\right)
$$

with the following two-point boundary conditions

$$
\begin{gathered}
v=1-x_{1} \text { at } x=0 \\
v \rightarrow 0 \text { as } x \rightarrow \infty .
\end{gathered}
$$

The computations were carried out with the aid of FERUT. Graphs and tables of $v(x)$ are available from the author for all the following cases:

$$
\begin{aligned}
& 1-x_{1}=0.01 \text { with } K=0.001,0.005,0.01,0.05,0.1,0.5,1, \text { and } 5 . \\
& 1-x_{1}=0.2 \text { with } K=0.001,0.005,0.01,0.05,0.1,0.5,1, \text { and } 5 . \\
& 1-x_{1}=0.4 \text { with } K=0.005,0.01,0.05,0.1,0.5,1,5, \text { and } 10 . \\
& 1-x_{1}=0.6 \text { with } K=0.01,0.05,0.1,0.5,1,5, \text { and } 10 . \\
& 1-x_{1}=0.8 \text { with } K=0.05,0.1,0.5,1,5,10,50, \text { and } 100 \\
& 1-x_{1}=0.9 \text { with } K=0.1,0.5,1,5,10,50, \text { and } 100 .
\end{aligned}
$$

A. H. T. 
47[V]. - Stefan Bergman, "Tables for the determination of fundamental solutions of equations in the theory of compressible fluids," $M T A C$, v. 9, p. 8-14, 1955.

The tables referred to in the title are tables of the functions $F_{n}(\lambda), T(\lambda)$ for complex values of the argument $\lambda$ where

$$
\begin{aligned}
\lambda & =\frac{1}{2} \log \left[\frac{1-T}{1+T}\left(\frac{1+h T}{1-h T}\right) \frac{1}{h}\right] \\
T & =\left(1-M^{2}\right)^{\frac{1}{2}} \\
h & =\left(\frac{\gamma-1}{\gamma+1}\right)^{\frac{3}{3}} \\
F_{n} & =(-1)^{n} \frac{(\gamma+1) M^{4}}{64}\left[\frac{a_{n} M^{4}+4(3-2 \gamma) M^{2}-16}{\left(1-M^{2}\right)^{3}}\right], \quad n=1,2 \\
a_{1} & =(3 \gamma-1), \quad a_{2}=\gamma-3 ;
\end{aligned}
$$

$\gamma$ is the ratio of specific heats presumably taken to satisfy $\gamma=7 / 5$. The arguments and functional values are given to four decimal places.

A. H. T.

\section{NOTES}

\section{Raymond Clare Archibald \\ 1875-1955}

Professor R. C. Archibald of Brown University, founder and editor of Mathematical Tables and Other Aids to Computation, died in Sackville, New Brunswick, July 26, 1955. He would have been 80 years of age on October 7 .

R. C. A., as readers of $M T A C$ knew him since 1943, had retired as editor in 1949. A portrait and an account of his life and his writings appeared at that time in $M T A C$, v. 4, 1950, p. 1-2. Since his retirement he had kept up an active interest in $M T A C$ contributing articles and reviews of tables. His special interest in tables began with his studies of mathematics. In 1908 he commenced the collection of tables for the Brown University Library which was to become the most important collection of its kind. His connection with the National Research Council began in 1939 when he assumed the chairmanship of its $M T A C$ committee. In a prophetic move, he saw the need of a periodical to further the exchange of information and ideas about tables and the art of computation. His high standards of scientific and bibliographic exactitude have been a challenge to the editors who have followed in his steps.

University of California

D. H. LEHMER

Berkeley, California 